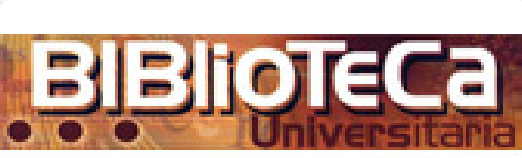

Biblioteca Universitaria

ISSN: 0187-750X

public@dgb.unam.mx

Universidad Nacional Autónoma de México

México

Palma Peña, Juan Miguel

Valores sociales y valores patrimoniales: elementos para determinar la significación del patrimonio documental

Biblioteca Universitaria, vol. 16, núm. 1, enero-junio, 2013, pp. 33-45

Universidad Nacional Autónoma de México

Distrito Federal, México

Disponible en: http://www.redalyc.org/articulo.oa?id=28528266004

- Cómo citar el artículo

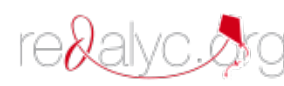

- Número completo

- Más información del artículo

Página de la revista en redalyc.org

Sistema de Información Científica

Red de Revistas Científicas de América Latina, el Caribe, España y Portugal

Proyecto académico sin fines de lucro, desarrollado bajo la iniciativa de acceso abierto 


\title{
Valores sociales y valores patrimoniales: elementos para determinar la significación del patrimonio documental
}

\author{
Social values and heritage values: elements to determine the \\ significance of documentary heritage
}

Juan Miguel Palma Peña*

\section{RESUImen}

La formación de valores es relevante para la sociedad, por lo que el presente documento se orienta a plantear que mediante el ejercicio con procesos cognitivos, informativos y vivenciales sobre valores sociales y valores patrimoniales, a través de espacios formales y no formales, se promueva en los ciudadanos actitudes y cualidades para que comprendan, determinen y tomen conciencia de la significación del patrimonio documental y, de esta manera, usufructúen racionalmente tal conjunto de expresiones informativas.

A partir de la revisión y el análisis de la literatura sobre el tema, el objetivo del presente documento es analizar la formación de valores sociales y patrimoniales como proceso que potenciará la significación racional del patrimonio documental mediante acciones informativas.

Se presentan cuatro apartados: primero, conceptos sobre el patrimonio bibliográfico y documental; segundo, proceso de formación de valores; tercero, valores sociales y valores patrimoniales para determinar la significación de la memoria documental; y cuarto, aspectos teóricos de una educación sobre patrimonio documental.

Palabras Clave: Valores sociales, valores patrimoniales, patrimonio bibliográfico, aprendizajes significativos, socialización del patrimonio, educación, patrimonio documental.

\section{Abstract}

Instilling values is relevant to society; so this paper promotes, by exercising cognitive, and experiential information about social values and heritage values through formal and informal spaces, citizen attitudes and qualifications to understand, identify and become aware of the significance of documentary heritage and, in this way, to rationally usufruct such set of information expressions.

From the review and analysis of the literature on the subject, the objective of this paper is to analyze the inculcation of social values and heritage values as a process that will enhance the rational significance of documentary heritage through information actions.

It has four sections: first, concepts of bibliographic and documentary heritage; second, the value instilling process; third, social values and heritage values to determine the significance of the documentary memory; and fourth, theoretical aspects of documentary heritage education.

KEYwORDs: Social values, heritage values, bibliographic heritage, significant learning, heritage socialization, education, documentary heritage

* Sistema de Información Académica HumANindex, Coordinación de Humanidades, Universidad Nacional Autónoma de México, (UnAm). Torre ॥ de Humanidades, Ciudad Universitaria, 04510 México, D.F. México. Correos electrónicos: jemajumi@ hotmail.com ; pueripulchermikael@gmail.com 


\section{Introducción}

E

I patrimonio bibliográfico y documental en el siglo XXI es valioso en la sociedad porque proporciona a los individuos identidad, conciencia, al igual que fortalece la diversidad cultural de la sociedad, a partir de la significación que poseen las expresiones producidas por las culturas del mundo.

La formación en valores -como proceso cultural y educativo- potencia usufructuar y salvaguardar la diversidad cultural y las expresiones producidas por las sociedades, así como impulsar que los ciudadanos construyan conocimientos humanísticos significativos, consoliden sus identidades nacionales, tomen conciencia, entre otros aspectos.

En materia bibliotecológica, la vinculación entre valores sociales y valores patrimoniales resalta -en principio- por contribuir a determinar la significación de las expresiones informativas, porque dichas manifestaciones son objeto de estudio de aquella disciplina, y también porque las bibliotecas al promover acciones de sensibilización, preservación, conservación, educación y difusión sobre la memoria documental, apoyan el avance humanístico y social. ${ }^{1}$

\section{Patrimonio bibliográfico y documental: conceptos ${ }^{2}$}

Algunas expresiones elaboradas por las sociedades desde épocas inmemoriales hasta las contemporáneas para informarse, comunicarse y sustentar su desarrollo son los libros y los documentos, ${ }^{3}$ los cuales son mani-

Una versión similar sobre el presente objeto de estudio, fue presentada como ponencia en el "I Congreso Iberoamericano sobre Patrimonio Cultural". 6-8 de Diciembre de 2010. Universidad de Costa Rica, Facultad de Ciencias Sociales, Ciudad Universitaria Rodrigo Facio. San José Costa Rica.

2 Palma, Juan Miguel. La educación sobre patrimonio bibliográfico y documental de la humanidad [en línea]. Tesis Maestría. México: UnAm, Facultad de Filosofía y Letras, Posgrado UNAM. 127 h. Resumen <http://universidadypatrimonio.net/ Thesis/2012PALMAPENYA218>, p. 2-4.

3 Son aquellos recursos impresos y digitales que tienen como finalidad informar y comunicar. Pueden considerase como una extensión de los libros. Su elaboración la realizan ciudadanos principalmente. festaciones del pensamiento humano útiles ${ }^{4}$ que han sido objetivadas en forma bibliográfica y documental, que son parte esencial del patrimonio cultural.

Para un conocimiento integral en torno al patrimonio bibliográfico y documental es necesaria una visión global ${ }^{5}$ del mismo ya que, no obstante la relevancia y el tratamiento que se ha realizado sobre el patrimonio cultural, aún es complejo saber " ... 1) en qué consiste el patrimonio cultural de un pueblo ... ; y 2) en qué radica su importancia ... para el común de la gente."6

Con base en algunos conceptos e interrogantes sobre patrimonio cultural, ${ }^{7}$ en una óptica bibliotecológica el patrimonio bibliográfico y documental puede comprenderse como: las expresiones artísticas, históricas, culturales, folklóricas, educativas, intelectuales, científicas, entre otras, que han sido producidas para ser testigo fiel del desarrollo de las sociedades; y que han sido objetivadas en manuscritos, impresos, medios audiovisuales, documentos electrónicos, etcétera, cuya finalidad es almacenar, transmitir, preservar, conservar, comunicar y difundir la suma de conocimientos que contienen.

Una clasificación en la que se aprecian los documentos que integran el patrimonio documental, en el caso de México, es la siguiente: ${ }^{8}$

4 Consiste en que los ciudadanos tanto en lo individual como en lo colectivo usufructúen los bienes documentales para distintas finalidades; al tener en cuenta la integridad de los mismos.

5 Se refiere a tomar en cuenta una serie de conceptos en torno al tema -en este documento sobre patrimonio bibliográfico y documental- a partir de los diferentes análisis y normatividades nacionales e internacionales. Es decir, impulsar una visión amplia, libre de barreras geográficas y etnocentrismos, equitativa e interdisciplinaria, por mencionar algunas. En: LLULL, Josué. Evolución del concepto y de la significación social del patrimonio cultural, p. 180.

6 BonfIL, Guillermo. Nuestro patrimonio cultural: un laberinto de significados, p. 19.

7 Véase Supra.

8 Fernández, Rosa. El Programa Memoria del Mundo de la unesco y los acervos patrimoniales de las bibliotecas públicas, p. 16. 
Colecciones de manuscritos: prehispánicos, coloniales, modernos, contemporáneos.

Colecciones de impresos: Siglo xv a la actualidad.

Colecciones de archivo: antiguas y modernas; administración pública y religiosa, archivos personales, de las propias bibliotecas y otras instituciones, ONG's.

Colecciones de microformatos: películas, fichas.

Colecciones o fondos audiovisuales: fotografías, discos, casetes, cd's, películas, diapositivas, archivos de radio y televisión.

Colecciones digitales: documentos digitales; portales web, libros, revistas.

La clasificación anterior expone la necesidad de que los ciudadanos de la sociedad actual reconozcan la diversidad de documentos que integran el patrimonio bibliográfico y documental, tanto nacional como internacional, en función de ampliar el panorama informativo de aquellos.

En este sentido, aún cuando el patrimonio bibliográfico y documental ha sido tratado en diversas esferas públicas y académicas, actualmente siguen pendientes tareas para su reconocimiento, valoración, organización, protección y difusión, para valorarlo en paralelo a los bienes muebles e inmuebles históricos.

Ante la diversidad de tareas inacabadas, el desarrollo de perspectivas educativas, informativas y difusoras sobre el patrimonio es latente; dicho pendiente pone de manifiesto el planteamiento de una educación flexible sobre patrimonio, propositiva, para desarrollar acciones educativas no formales, y cuyos objetivos sean: rescatar, conservar, transmitir, almacenar, comunicar y difundir la información que posee la memoria documental, con base en la significación de aquel conjunto.

\section{Significación del patrimonio bibliográfico y documental}

La significación del patrimonio bibliográfico y documental consiste en la relevancia que posea determinado documento y según los fines para los que sea utilizado. En ella se conjugan la relevancia del todo de las manifestaciones, tanto internas como externas.

Para determinar la significación del patrimonio bibliográfico y documental se puede utilizar un conjunto de valores sociales que han sido desarrollados por las culturas desde tiempos inmemorables, así como algunos valores promovidos en espacios educativos, a partir de un consenso colectivo.

El valor se refiere a la construcción mental que hace algún individuo o grupo sobre la importancia que posee determinado conjunto de manifestaciones y representaciones que la humanidad ha producido, y en términos generales se determina la significación con valores que dan sentido a la vida. ${ }^{9}$

Para el patrimonio documental, los valores sociales podrán impulsar lo siguiente: potenciar la comprensión del pasado de la humanidad, permitir entender el presente y dilucidar el futuro, construir identidad, proteger raíces culturales, tomar conciencia, ${ }^{10}$ ejercer

9 Valores dan esencia a la vida porque a partir de su concientización, usufructo y reproducción, los individuos podrán apreciar con diversos enfoques el conjunto de manifestaciones y representaciones sociales, ya sean cotidianas, históricas, culturales, entre otras, para fortalecer su identidad.

10 Se refiere al desarrollo de juicios morales racionales y el ejercicio de los mismos por parte de los individuos, con base en los valores que heredan culturalmente y adquieren mediante la asimilación y la acomodación de acuerdo a sus necesidades personales y colectivas. La conciencia posibilitará a los ciudadanos apreciar desde diversas perspectivas la vasta diversidad de manifestaciones y representaciones materiales y no materiales producidas por la humanidad. El proceso mediante el cual se podrá promover dicha conciencia es la educación, ya que a través de ésta los individuos podrán interiorizar los valores, así como ampliar su panorama informativo, reflexivo y dialógico, con la finalidad de formar ciudadanos conscientes y responsables socialmente. 


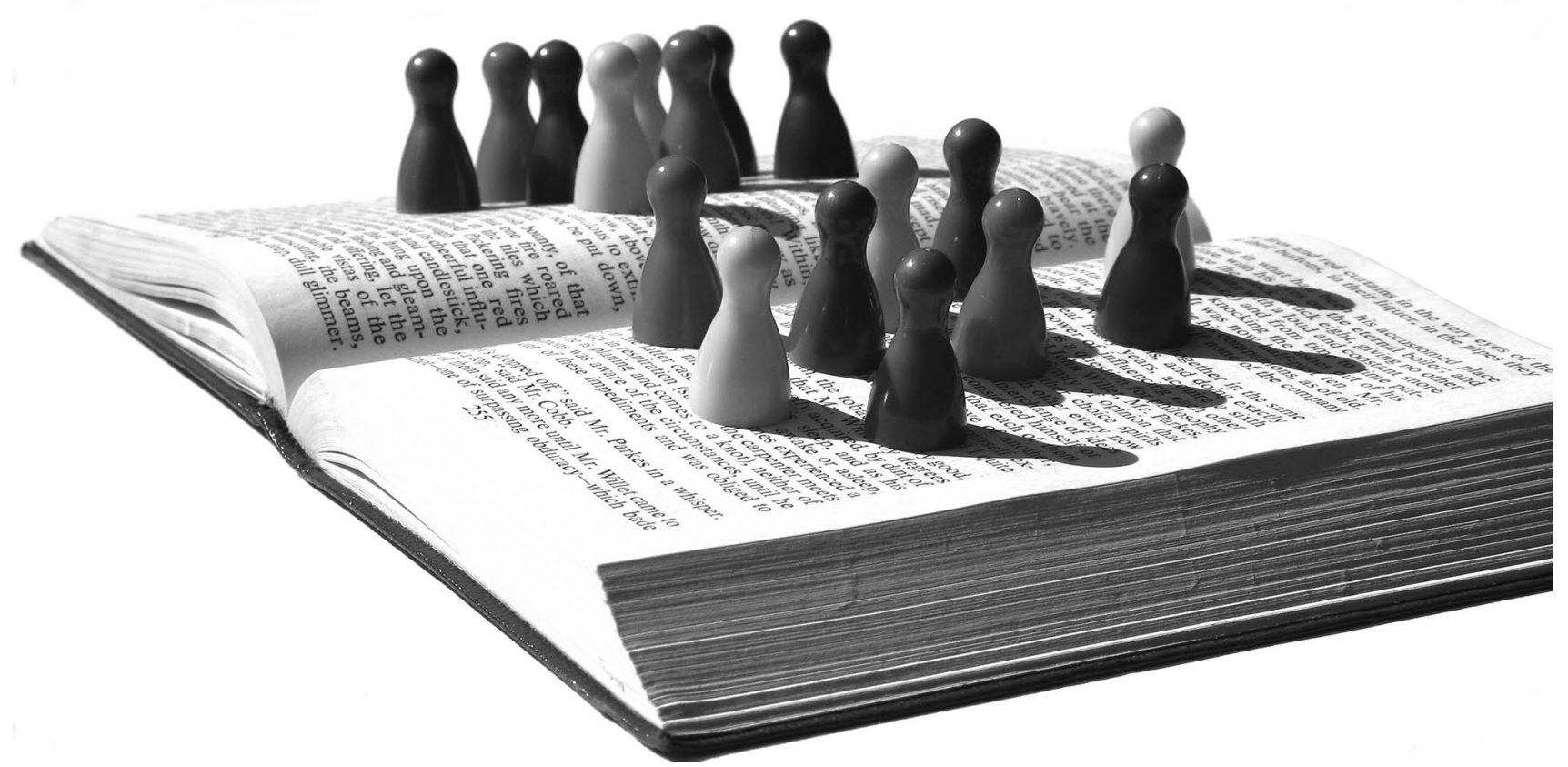

democracia, impulsar el desarrollo, realizar constante ejercicio crítico-creativo, ${ }^{11}$ entre otros aspectos. Para incrementar la adquisición de elementos que posibiliten determinar la significación de las expresiones es requisito una formación en valores.

La formación en valores tiene planteamientos teóricos para el desarrollo de una sociedad altamente educada, ${ }^{12}$ en función de que los ciudadanos adquieran atributos en consenso para comprender la trascendencia de la humanidad, la historia, la identidad cultural y un espíritu nacionalista. ${ }^{13}$

11 Permitirá a los ciudadanos una mejor comprensión sobre la relevancia que implica proteger el patrimonio bibliográfico y documental de la humanidad, mismo patrimonio que se caracteriza por ser el medio para la sostenibilidad cultural de las generaciones futuras. Este pensamiento tiene fines educativos, los cuales podrán asegurar la permanencia del patrimonio al difundirlo mediante diversas acciones educativas formales e informales. Morales, Estela. ¿Por qué estudiar bibliotecología? Ponencia presentada en la XVII Reunión del Consejo para Asuntos Bibliotecarios, 2001, p. 8. En: Ríos, Jaime. Didáctica de la bibliotecología: teoría y principios desde la enseñanza, p. 119-120.

12 SchmelKes, Sylvia. La formación de valores en la educación básica, p. 14.

13 DeLoRs, Jacques. Learning: the treasure within. París: UNESCO, 1996. En Schmelkes, Sylvia, op. cit, p. 15.
El desarrollo cognitivo de los ciudadanos es uno de los principios de la formación en valores, ya que el proceso de racionalidad ${ }^{14} \mathrm{y}$ crítica que hagan los individuos sobre algún objeto de estudio les permitirá reconocer la relevancia de las prácticas y los productos sociales.

\section{Formación en valores}

La formación en valores es un proceso individual en el que se lleva a cabo un juicio moral, ${ }^{15}$ para que al momento de situaciones morales se tomen decisiones morales significativas. ${ }^{16}$

14 "La racionalidad es el juego, el diálogo incesante, entre nuestro espíritu, que crea las estructuras lógicas, que las aplica al mundo, y que dialoga con ese mundo real". Morin, Edgar. Introducción al pensamiento complejo, p. 102.

15 Schmelkes, Sylvia, op. cit, p. 52-54.

16 Son aquellas que mediante un juicio moral y una reflexión sobre determinadas situaciones permite establecer decisiones deliberadas con relevancia para futuras situaciones. La significatividad estará encaminada a que las decisiones tomadas sean relevantes en función de que al ser reflexionadas reflejen su aportación. 
En la formación de valores intervienen cuatro actores, y son los siguientes: la familia, los docentes, ${ }^{17}$ los estudiantes y las instituciones de educación, en las que figuran las bibliotecas.

Sobre los docentes, éstos deberán reflejar lo que quieren transmitir para emprender la mejora del estado epistémico ${ }^{18}$ de los estudiantes. En la perspectiva docente, algunos elementos para una educación en valores son: ${ }^{19}$

- Establecer un contexto para el diálogo, la comunicación, la confianza, el respeto, la aceptación, la crítica, la reflexión y la discusión de problemas.

- Promover la difusión mediante la oralidad y la escritura, ya que ésta es un medio racional que promueve el juicio moral y el análisis crítico. ${ }^{20}$

- Utilizar conceptos ya existentes, cuyo proceso se denomina asimilación. ${ }^{21}$

- Provocar desequilibrio conceptual; dicho proceso se denomina acomodación. ${ }^{22}$

17 Kohlberg, Lawrence. Prólogo. En Reimer [et al]. Promoting moral growth: from Piaget to Kohlberg. Prospect Height, Waveland. Véase Schemelkes, Sylvia, op. cit. p. 63.

18 Está relacionada con la estructura de ideas, pensamientos, conceptos e información que adquieren los estudiantes tanto en sus experiencias previas como aquellos que construyen a través de procesos educativos. El resultado de esta integración deberá ser que los estudiantes tomen decisiones adecuadas, reflexionen, proporcionen juicios críticos, entre otros.

19 Schemelkes, Sylvia, op. cit., p. 64.

20 En sociedades letradas.

21 Proceso en que los ciudadanos a partir de sus experiencias previas, y conceptos existentes, los emplean para trabajar con nuevos conocimientos. En: Acomodación de un concepto científico: hacia una teoría del cambio conceptual, p. 91.

22 Proceso en que los ciudadanos, al momento en que sus conocimientos preexistentes son inadecuados para asimilar los conceptos nuevos, deben reemplazar o reorganizar sus conceptos generales. En: Acomodación de un concepto científico: hacia una teoría del cambio conceptual, p. 91.
- La intersubjetividad. ${ }^{23} \mathrm{~A}$ partir de nuevas concepciones aceptadas en lo individual, es relevante la credibilidad de la comunidad para fortalecer la validez de las interpretaciones.

Los elementos anteriores se encaminan en beneficio de ampliar el espectro valorativo de los estudiantes. Al respecto de éstos, son los principales destinatarios y futuros desarrolladores de una sociedad educada, conciente, humanizada, ${ }^{24}$ con capacidad de asimilar y acomodar ${ }^{25}$ constantemente información. Por lo que el proceso de formación de valores posibilitará acercar a los ciudadanos con las manifestaciones para ejercitar la valoración.

Algunos objetivos que se buscan para la formación en valores en los estudiantes son los siguientes: ${ }^{26}$ aprender a aprender, aprender a adquirir conocimiento, aprender a aprovechar el conocimiento obtenido, practicar la lectura, tener actitud reflexiva y abierta al aprendizaje para toda la vida, ${ }^{27}$ relacionarse mediante el diálogo y la disertación, realizar trabajos colaborativos y tener actitud autodidacta.

23 Se refiere a la formulación de creencias a partir de la aceptación de las interpretaciones realizadas por los individuos. Impulsa la interacción social en la que las bibliotecas tienen amplia ingerencia. Se trata de cómo fijar la creencia, no sólo del individuo, sino de la comunidad, en búsqueda de legitimidad y credibilidad de las interpretaciones. La intersubjetividad es la segunda prueba de validez para la interpretación de textos, la cual es parte del círculo hermenéutico Véase Armstrong, Paul B. Lecturas en conflicto: validez y variedad en la interpretación, p. 13.

24 La humanización de los individuos se refiere a que a través de la educación se les proporcionará las bases epistemológicas y empíricas para que asimilen y acomoden las manifestaciones y las representaciones de la cultura.

25 Proceso considerado paralelo al de la vida humana. En: VILLALPANDO, José Manuel. Filosofía de la Educación, p. 87.

26 Morales, Estela. El uso de la información y la reflexión, condiciones para llegar a la universidad del conocimiento, p. 73-74.

27 Democratización de la educación es uno de los objetivos del Informe de seguimiento de la EPT [en línea]: educación para todos en 2015 ¿alcanzaremos la meta? <http://unesdoc. unesco.org/images/0015/001548/154820s.pdf> 
El tercer actor en el proceso de formación en valores son las instituciones de educación superior, en las que figuran las bibliotecas. Su principal premisa podrá consistir en que tanto docentes como estudiantes adquieran conciencia sobre la representatividad de las manifestaciones informativas, impulsadas por las actividades bibliotecarias.

Para la formación de valores en bibliotecas, transversalizar $^{28}$ el constructivismo ${ }^{29}$ con la perspectiva bibliotecológica apunta por desarrollar estrategias de aprendizaje para la adquisición y la acomodación de información, y que los ciudadanos construyan conocimientos significativos. ${ }^{30}$

Lo anterior, corresponde a que en los espacios educativos -formales ${ }^{31}$ y no formales ${ }^{32}$ - se busca impulsar que las ideas, las representaciones y la información sean tanto construidas como acomodadas por los ciudadanos en una cultura del aprendizaje. ${ }^{33}$

28 La transversalización propuesta se desarrolla de acuerdo a los tipos de constructivismo: epistemológico, instruccional y social. Se plantea como una relación entre posturas constructivistas y educación en valores. En: DíAz-BARriga, Frida. Estrategias docentes para un aprendizaje significativo: una interpretación constructivista, p. 29; Pozo, Juan Ignacio. Aprendices y maestros: la psicología cognitiva del aprendizaje, p. 136-137.

29 "El constructivismo tiene tres ejes, que son los contenidos: qué se aprende; los procesos: cómo se aprende, y las condiciones: entornos para el aprendizaje." En: PICARdo, Oscar, op cit.

30 Se refieren a las habilidades de los individuos para conjuntar sus conocimientos previos y sus capacidades cognitivas desarrolladas, para encaminarlas hacia la toma de conciencia, mejorar la solución de problemas y valorar las manifestaciones, y así que éstas sean usufructuadas y salvaguardadas.

31 Se desarrolla en espacios presenciales. Posee estructura curricular. Tiene como fin mejorar el estado epistémico de los individuos. Los tipos de educación son: básica, media superior, superior y posgrado.

32 Se proporciona con actividades informativo-divulgativas. No posee estructura curricular. Tiene fines educativos intrínsecos, tales como: la toma de conciencia, la estructuración y la asimilación de ideas, la amplitud del panorama informativo sobre alguna área del conocimiento, entre otras. Algunas actividades son: exposiciones, visitas guiadas, conferencias, entre otros.

33 Pozo, Juan, op. cit., p. 67-120.
El dinamismo de la sociedad manifiesta que el análisis de la cultura ${ }^{34}$ requiere abordarse con una perspectiva global, ${ }^{35}$ en la que se comprenda que aquella es una construcción histórica y contemporánea, integrada por elementos renovables que permitan identificar y usufructuar las representaciones culturales.

Se considera que las bibliotecas en relación con la cultura a través de la transmisión de habilidade ${ }^{36}$ podrán articular el proceso educativo para que mediante el acceso a la información se apoye el inicio, el desarrollo y la conclusión de actividades formativas de los individuos en función de su progreso social, educativo y cultural; tal progreso será con base en una cultura del aprendizaje, la cual se caracterice por fomentar aprendizajes comprometidos, significativos, críticos y reflexivos.

En suma, en las instituciones de educación superior, díganse bibliotecas, se puede optar por construir y difundir una cultura del aprendizaje, en la que se integre e impulse la formación de valores sociales y patrimoniales en consonancia con las necesidades cognitivas de la comunidad y la sociedad actual.

34 La cultura se refiere al "conjunto de los rasgos distintivos espirituales y materiales, intelectuales y afectivos que caracterizan a una sociedad o a un grupo social y que abarca, además de las artes y las letras, los modos de vida, las maneras de vivir juntos, los sistemas de valores, las tradiciones y las creencias." En: UNESCO. Declaración universal de la UNESCO sobre la diversidad cultural [en línea]. Organización de las Naciones Unidas para la Educación, la Ciencia y la Cultura, 2001. <http://portal.unesco.org/es/ev.php-URL_ID=13179\&URL_ DO=DO_TOPIC\&URL_SECTION=201.html>

35 La globalización con perspectiva informativa, cultural y educativa, es el proceso mediante el cual los elementos interculturales, multiculturales, educativos, históricos, entre otros, se internacionalizan. El principal objetivo de esta globalización es proporcionar prosperidad a las sociedades mundiales, que aprovechen la información, fortalezcan las interrelaciones, refuercen las identidades, eliminen cualquier tipo de discriminación, incrementen la curiosidad de los ciudadanos, entre otros. Esta perspectiva es de carácter integrador y se suma a las perspectivas económicas que posee la globalización.

36 SherA, Jesse. Lo que el bibliotecario necesita saber, p. 212. 


\section{Valores sociales}

Algunos elementos para el desarrollo humano y la formación de sociedades conscientes en el siglo XXI son los valores sociales. ${ }^{37} \mathrm{~A}$ partir de éstos se podrán lograr las siguientes ventajas: ciudadanos con actitudes y cualidades para la solución de problemas, crítica de los hechos, compromiso y participación con la sociedad, ${ }^{38}$ entre otras.

Se consideran tres las formas en que los ciudadanos adoptan valores sociales: primero, valores heredados; segundo, valores desarrollados en educación formal; $y$ tercero, valores desarrollados en educación no formal.

La vinculación entre valores ${ }^{39}$ y educación radica en que los primeros representan la esencia humana, ${ }^{40}$ ya que posibilitan el reconocimiento de esfuerzos individuales y sociales depositados en las manifestaciones producidas; dicho reconocimiento es denominado conciencia del valor. ${ }^{41}$ Respecto a la educación, ésta se considera como el medio para la transmisión y el intercambio de valores, así como por inducir la humanización de los individuos. Entre los valores y la educación, la actitud de los individuos será prioritaria ya que favorecerá que los sujetos realicen juicios de valor, ${ }^{42}$ para estimar la valia de las manifestaciones. ${ }^{43}$

37 CASA, Beatriz. La formación de valores en la educación superior: el caso de la carrera de Bibliotecología y Estudios de la Información, p. 52.

38 Ibid, p. 16.

39 Los valores son " ... esencias, cualidades ideales, la particularización ... de una actitud racional, de reconocimiento, de cotejo con la naturaleza personal, de identificación o diversificación de ella, de aceptación o de repulsa, de afán de realización plena, de apropiación cabal, y hasta de modelación de la persona en razón de tales valores." En: VILLALPANDO, José, op. cit., p. 133-134.

40 Villalpando, José, op. cit., p. 133.

41 "La conciencia del valor es una actitud generalizada ante todo lo que representa una forma cultural ... " En: Villalpando, José, op. cit., p. 133.

42 Ibid, p. 134

43 En el juicio de valor la relevancia de las manifestaciones pasan a segundo plano sin demeritarlas.
Otro factor posible a considerar para la formación de valores es el usufructo ${ }^{44}$ de las representaciones sociales, mismo proceso en el que están inmersos los valores y los intereses individuales. ${ }^{45}$

Elaborar una lista de valores sociales resultaría restrictivo, debido a la complejidad por representar aquellos aceptados socialmente; por tanto, es pertinente presentar los valores de sociedades letradas ${ }^{46}$ que de acuerdo con el presente documento son los siguientes: ${ }^{47}$ educación, responsabilidad, sinceridad, diálogo, confianza, autoestima, creatividad, paz, amistad, respeto, justicia, cooperación, observación, compartición, identidad, crítica, autonomía, reflexión, entre otros.

Para lograr que los valores sociales anotados anteriormente impacten significativamente en la sociedad es requisito que los integrantes de la misma los interioricen a través de entornos formales y no formales. El nexo entre los valores sociales, los entornos y las manifestaciones culturales se articula para desarrollar tanto perspectivas informativas como contenidos educativos e impulsar la comprensión razonada por parte de los individuos.

En suma, se plantean dos posturas sobre valores sociales para este documento: primera, impulsar la formación en valores sociales como elementos para la toma de conciencia de los individuos y, así, que estimen las manifestaciones socioculturales con perspectivas informativas heredadas y desarrolladas educativamente; segunda, promover la valoración de las representaciones informativas por medio de valores patrimoniales, los cuales pueden ser difundidos en procesos educativos.

\footnotetext{
44 Formas en que se aprecia, disfruta y se utilizan las manifestaciones sociales.

45 Valoración denominada vivencia del valor. En: VilLalpando, José, op. cit., p. 134.

46 En las sociedades letradas los individuos en situación de aprendizaje realizan juicios morales, reflexionan, dialogan, debaten, entre otros, a partir de los valores que ha desarrollado desde su cultura, así como los que se le han sido presentados en los procesos de enseñanza-aprendizaje. Esta postura educativa no se refiere a la educación como un proceso pasivo intelectual tradicional.

47 CARreras, Llorenc. Cómo educar en valores: materiales, textos, recursos y técnicas, p. 312 p.
} 


\section{Valores patrimoniales}

Para valorar las manifestaciones informativas se pueden utilizar criterios consensuados, los cuales se denominan valores patrimoniales. Mediante éstos se podrá lograr lo siguiente: determinar la valía de las representaciones documentales, impulsar que los ciudadanos conozcan y usufructúen el legado que protegen, incrementar el acceso, la democratización, la prevención, la conservación y la protección de la herencia documental, así como promover en los ciudadanos comprensiones racionales y vivenciales de las particularidades materiales, simbólicas, espirituales, históricas e informativas que constituyen al patrimonio documental.

Teóricamente, un vehículo que puede utilizarse para socializar y asegurar la permanencia del patrimonio es la educación, mismo proceso que al ser por los individuos y para los individuos potenciará el progreso y la superación de las culturas al promover la estimación, la toma de conciencia y el uso de las expresiones culturales.

Educación, valores sociales y valores patrimoniales se articulan para promover apreciaciones morales, vivenciales y culturales respectivamente, en razón de la estabilidad de la memoria documental. En la valoración patrimonial con perspectiva educativa participan docentes, estudiantes e instituciones de educación superior incluidas las bibliotecas.

Se puede considerar que la valoración del patrimonio en el contexto educativo se podrá articular con dos enfoques: primero la educación formal, con previa selección del conjunto de particularidades significativas que poseen las manifestaciones documentales, lo que manifiesta un proceso deductivo; $y$, segundo, la educación no formal, en la que los individuos a partir de necesidades e intereses personales seleccionen y determinen las expresiones a valorar, lo que representa un proceso inductivo.

La participación de los docentes para potenciar la valoración se podrá dar en dos sentidos: 1) a través de la observación de necesidades e intereses de los estudiantes, y así promover las expresiones que complementarán el desarrollo formativo de los individuos; y 2) mediante el autodidactismo, en el que los docentes podrán inducir a los individuos en la elección consciente de las manifestaciones para su desarrollo cultural personal. ${ }^{48}$

Por su parte, la vivencia como parte de los valores patrimoniales es relevante por ser “... una vivencia de clase particular que puede llevarse a cabo de un modo preferentemente sentimental (es decir, con movimiento interior), o de un modo dominantemente intelectual (es decir, con íntimo reposo) ...".49 A partir de la vivencia del valor los individuos podrán comprender el significado de las manifestaciones culturales, mediante la conjugación de racionalidad, experiencia, apreciación e intereses personales.

Algunos valores patrimoniales que permitirán determinar la significación de las expresiones con óptica bibliotecológica son los siguientes: ${ }^{50}$ protector-difusor, ${ }^{51}$ acceso a la información registrada, educación y progreso..$^{52}$

En paralelo a los valores anteriores, algunas particularidades para valorar libros y documentos son las siguientes: intelectuales, ${ }^{53}$ materiales, ${ }^{54}$ gráficas, ${ }^{55}$

48 Villalpando, José, op. cit., p. 137.

49 Messer, August. Filosofía y educación. Buenos Aires: Losada, 1949. p. 138. En: VILLALPANDo, José, op. cit., p. 147.

50 Gorman, Michael. Our enduring values: librarianship in the 21 st century, p. 26-28

51 La relevancia de este valor radica en tres objetivos: el primero, preservar los registros de información; el segundo, promover que las futuras generaciones bibliotecológicas tengan conocimientos sobre los objetos de estudios de la disciplina y los valores que guían la práctica bibliotecaria; y el tercero, proporcionar estrategias de preservación sobre la memoria documental.

52 Otros valores en la perspectiva bibliotecológica que han sido planteados para regular la identidad social son: autorrealización, democracia, libertad, educación y progreso. En Rıs, Jaime. La biblioteca pública: un lugar de valores, p. 322.

53 Se refieren a la temática que trata el documento.

54 Consisten en identificar la materia que poseen los documentos desde su producción. Este tipo de particularidades se denominan como valor textual.

55 Tratan las representaciones que ilustran la temática del documento. 
sociales ${ }^{56}$ históricas, ${ }^{57}$ influencia, periodo, lugar, vida y obra de una persona, asunto o tema, forma y estilo, y valor excepcional, sea social, cultural o espiritual. ${ }^{58}$

El par de conjuntos de valores patrimoniales mencionados se consideran en razón de cuatro finalidades para este trabajo:

1. Responder en qué radica la importancia ${ }^{59}$ del patrimonio documental.

2. Identificar particularidades de documentos para su estabilidad; ${ }^{60}$ preservar, conservar y socializar aquel a través de las bibliotecas.

3. Que los criterios mencionados permitan a nivel nacional y local analizar, identificar, registrar, sensibilizar ${ }^{61}$ y salvaguardar para potenciar el acceso al patrimonio documental.

4. Que los ciudadanos realicen juicios morales y conscientes para apreciar las expresiones documentales a partir de actividades promovidas en bibliotecas y otros centros de información. ${ }^{62}$

56 Aportaciones culturales, educativas, científicas, etcétera, de los documentos para un determinado grupo humano.

57 Relevancia que los documentos han tenido durante algún período de la humanidad. Este factor se refiere a las características que las representaciones han adquirido a través de la historia. Se les ha denominado como valor histórico.

58 Rıos, Jaime. La biblioteca pública: un lugar de valores, p. 16-17.

59 Véase Supra p. 3.

60 UNesco. Memoria del mundo [en línea]: directrices para la salvaguarda del patrimonio documental. Organización de las Naciones Unidas para la Educación, la Ciencia y la Cultura, 2002. 63 p. <http://unesdoc.unesco.org/ images/0012/001256/125637s.pdp $>$

61 Entre los medios que se emplearán para la sensibilización sobre el patrimonio documental, y que tienen relación con este documento, destacan la educación y la difusión de información.

62 Otros centros de información que resguardan el patrimonio bibliográfico y documental son: hemerotecas, museos, galerías de arte, etcétera.
El interés porque los valores patrimoniales sean difundidos en procesos educativos formales y no formales radica en que aquellos " ... son importantes y decisivos para la dinámica de las culturas cuando son muchas las comunidades que los aceptan y reproducen a lo largo del tiempo en un proceso intergeneracional".63

En suma, las escuelas y las bibliotecas como instituciones sociales deberán asumir la responsabilidad de apoyar la construcción de sociedades humanizadas con base en la información y el ejercicio de sus derechos humanos y culturales.

\section{Educación sobre patrimonio bibliográfico y documental: reflexiones para su desarrollo en la sociedad del siglo $x x$}

El dinamismo de la sociedad actual ha manifestado la necesidad de repensar los procesos educativos de las instituciones, tales como los realizados por la universidad con apoyo de las bibliotecas universitarias.

En las innovaciones educativas, las estrategias vivenciales en espacios formales y no formales representan una opción para garantizar la estabilidad del patrimonio, así como mejorar la forma en que los ciudadanos aprenden y toman conciencia para asegurar el usufructo y la salvaguarda del conjunto patrimonial, y de esta forma que el acto educativo sirva para el futuro.

Dos formas se pueden considerar para lograr que el aprendizaje sea útil para el futuro: ${ }^{64}$

1. Promover que mediante la educación y la estructura ${ }^{65}$ de currículos los estudiantes organicen y construyan conocimientos sobre lo que se busca significar.

\footnotetext{
63 Mendes, Sivio. Valores, patrimonio edificado y ciberespacio [en línea]. En: unesco. Museum Internacional 215: Heritage issues in the information society, 1. p. 23. <http://portal.unesco. org/culture/es/files/18662/10909215305museum215. $\mathrm{pdf} /$ museum215.pdf>

64 BRUner, Jerome. El proceso de la educación, p. 26.

65 Consiste en relacionar significativamente las cosas. Ibid., p. 11.
} 
2. Que con base en ideas generales ${ }^{66}$-teóricamente- los estudiantes comprendan ideas fundamentales. ${ }^{67}$

La educación propuesta apunta a considerar la estructuración de contenidos fundamentales sobre el legado informativo e instruir con base en ideas generales la construcción de conocimientos significativos sobre aquel conjunto. La misión de la educación sobre patrimonio es informar y formar sobre las manifestaciones documentales a los ciudadanos con apoyo de las bibliotecas, las cuales han sido un medio por antonomasia que lo ha protegido y transmitido.

La visión de la educación planteada es que con base en valores sociales, valores patrimoniales, análisis, reflexión, investigación, autodidactismo, diálogo y disertación, se analice multidisciplinariamente al patrimonio, para fortalecer su carácter teórico y empírico en espacios bibliotecarios.

Lo anterior deriva en que las bibliotecas, al ser espacios propicios para el desarrollo de la educación formal, marco para la educación no formal y para que los ciudadanos conozcan y aprecien el patrimonio, impulsen la significación del patrimonio con base en servicios de información, tales como: entornos presenciales y digitales, puntos de acceso, alfabetización informativa sobre patrimonio, entre otros. En las actividades bibliotecarias sobre el patrimonio podrá considerarse el uso de tecnologías de la información y la comunicación (Tic) como apoyo para el intercambio de información con los ciudadanos.

En el planteamiento de la educación sobre patrimonio documental podrán coadyuvarse procesos de asimilación y acomodación conceptual, ${ }^{68}$ impulsar la sensibilización, la comprensión y la apreciación de los contenidos teóricos con perspectivas constructivistas y pragmáticas.

Se puede precisar que la educación formal, el patrimonio bibliográfico y documental y las bibliotecas, son

66 Ibid., p. 27.

67 Lo fundamental consiste en que una idea tiene aplicabilidad amplia y potente. Ibid., p. 28.

68 Concepto sobre acomodación conceptual, véase supra p. 6-7. elementos principales para la construcción histórica y cultural de la sociedad actual y del sistema educativo respecto a dicho objeto de estudio. Por lo que en la medida en que se transversalicen aspectos multidisciplinarios, actividades informativas y empíricas, los ciudadanos podrán desarrollar construcciones cognitivas sólidas sobre aquel conjunto.

En suma, ante la diversidad de entornos educativos para desarrollar procesos de enseñanza-aprendizaje sobre patrimonio documental, la educación no formal -en la que figuran las bibliotecas- se considera un marco flexible e idóneo para desarrollar con perspectiva informativa, racional y empírica la comprensión individual y colectiva de la representatividad del patrimonio documental en el mundo actual.

\section{Consideraciones finales}

El dinamismo y la complejidad de los procesos sociales contemporáneos, requiere de atributos para que los ciudadanos realicen juicios morales y de valor para estimar la significación de las manifestaciones, que a su vez impulsen la toma de conciencia y fortalezcan la identidad cultural.

Es pertinente considerar que las instituciones educativas contemplen la integración de procesos educativos constructivistas en los currículos educativos, para que los estudiantes adquieran conocimientos metodológicos y empíricos para asimilar, acomodar y construir conocimientos significativos sobre patrimonio.

En la disciplina bibliotecológica, la formación en valores es relevante ya que deberá comprenderse como proceso inherente a las responsabilidades sociales de las bibliotecas, por lo que la misión de los bibliotecólogos deberá encaminarse a que desarrollen valores sociales y patrimoniales para estimar la valia de los procesos sociales y sus elaboraciones socioculturales, especificamente las objetivadas en forma bibliográfica y documental.

Es relevante comprender que mediante la formación en valores las bibliotecas podrán fortalecer su participación en los procesos socioeducativos contemporáneos. 
Debido a que -entre otras acciones- podrán: apoyar el proceso cognitivo de asimilación y acomodación de los ciudadanos; democratizar el acceso a la información con distintos puntos de acceso y servicios bibliotecarios; impulsar la toma de conciencia a través de acciones bibliotecarias relacionadas con los valores sociales y los valores patrimoniales; ampliar el panorama informativo y documental de los ciudadanos; estimular la sensibilización mediante la vivencia del patrimonio.

Aún quedan pendientes tareas relacionadas con la formación de valores y la valoración de la memoria informativa en aspectos como: la diversidad cultural, las estrategias de enseñanza-aprendizaje formales y no formales, los paradigmas tecnológicos e informáticos, los usos de los valores, entre otros.

Finalmente, con base en lo planteado en este documento se propone que aquellos asuntos pendientes tengan como premisa que tanto con valores sociales como con valores patrimoniales se articulará la protección racional y fundamentada de la memoria documental, en función de prolongar su permanencia para su usufructo educativo, informativo, vivencial, recreativo y responsable de aquel conjunto. $\boldsymbol{o s}_{3}$

\section{Obras Consultadas}

Abdelaziz, Abid. Memoria del Mundo: conservando nuestro patrimonio documental. México: Comisión Nacional de los Estados Unidos Mexicanos para la UnESCo: UnAM, 1998. 39 p.

Acomodación de un concepto científico: hacia una teoría del cambio conceptual. G.J. Posner, K.A. Strike, P.W. Hewson, W.A. Gertzog. En: Porlán, Rafael. Constructivismo y enseñanza de las ciencias. España: DIADA, 1995. p. 91-114.

Armstrong, Paul B. Lecturas en conflicto: validez y variedad en la interpretación. México: unAm, 1992. 157 p.

BonfiL, Guillermo. Nuestro patrimonio cultural: un laberinto de significados. En: El patrimonio cultural de México. E. Florescano, comp. México: CNCA: Fondo de Cultura Económica, 1993. p. 19-40.

Bruner, Jerome. El proceso de la educación. Traductor Carlos Palomar. México: utehA, 1963. 141 p.

CARreras, Llorenc. Cómo educar en valores: materiales, textos, recursos y técnicas. Madrid: Nareca, 2001. 312 p.

CASA, Beatriz. La formación de valores en la educación superior: el caso de la carrera de Bibliotecología y Estudios de la Información. En: Anuario de Bibliotecologia y Estudios de la Información. México: Universidad Nacional Autónoma de México, Facultad de Filosofía y Letras, 2008. Vol. 1, p. 13-25.

DíAz-BARRIGa, Frida. Estrategias docentes para un aprendizaje significativo: una interpretación constructivista. México: McGraw-Hill, 2002. 232 p.

Fenstermacher, Gay, Soltis, Jonas. Enfoques de la enseñanza. Argentina: Amorrortu, 1999. 216 p. 
Fernández, Rosa. El Programa Memoria del Mundo de la unesco y los acervos patrimoniales de las bibliotecas públicas. En: El bibliotecario v. 6, no. 65, p. 15-22.

Gorman, Michael. Our enduring values: librarianship in the 21st century. Chicago: American Library Association, 2000. 188 p.

Informe de seguimiento de la EPT [en línea]: educación para todos en 2015 ¿alcanzaremos la meta? UNESCO. Paris: UNESCO, 2007. 49 p. <http://unesdoc.unesco.org/images/0015/001548/154820s.pdf> [Consulta: febrero 2010].

LLULL, Josué. Evolución del concepto y de la significación social del patrimonio cultural. Arte, individuo y sociedad. V. 17. pp. 177-206.

Mendes, Sivio. Valores, patrimonio edificado y ciberespacio [en línea]. En: unesco. Museum Internacional 215: Heritage issues in the information society, 1. p. 21-32. < http://portal.unesco.org/culture/es/files/18662/109092153 05museum215.pdf/museum215.pdf> [Consulta: enero 2009].

Morales, Estela. El uso de la información y la reflexión, condiciones para llegar a la universidad del conocimiento. Infodiversidad, Sociedad de Investigaciones Bibliotecológicas, año/ vol. 7. 2004. pp. 63-75.

MorIn, Edgar. Introducción al pensamiento complejo. Barcelona: Gedisa, 1995. 167 p.

El multiculturalismo y los servicios de información. Coord. Estela Morales Campos; colab. Beatriz Casa Tirao, et. al. México: unam, Centro Universitario de Investigaciones Bibliotecológicas, 2007. 105 p.

Palma, Juan Miguel. La educación sobre patrimonio bibliográfico y documental de la humanidad [en línea]. Tesis Maestría. México: unam Facultad de Filosofía y Letras, Posgrado unam. 127 h. Resumen < http:/ universidadypatrimonio.net/ Thesis/2012PALMAPENYA218_ES.pdf> [Consulta: febrero 2013].

La formación de valores sociales y valores patrimoniales: binomio esencial para determinar la significación del patrimonio bibliográfico y documental. En: Congreso Iberoamericano sobre Patrimonio Cultural (1: 2010: San José, Costa Rica) I Congreso Iberoamericano sobre Patrimonio Cultural. Costa Rica: Universidad de Costa Rica, 2010. En prensa.

La socialización del patrimonio bibliográfico y documental de la humanidad desde la perspectiva de los derechos culturales [en línea]. Revista General de Información y Documentación, v. 21, p. 291-312. <http://revistas. ucm.es/index.php/RGID/article/view/291-312> [Consulta: junio 2012].

La socialización del patrimonio bibliográfico y documental de la humanidad. En: Jornadas Mexicanas de Biblioteconomía (41: 2010: Zacatecas, México). XLI Jornadas Mexicanas de Biblioteconomía: memorias. México: AMBAC, 2010. En prensa.

Valores sociales y valores patrimoniales: elementos para la educación sobre patrimonio documental ante el dinamismo de la sociedad del siglo XxI. En: Jornadas Mexicanas de Biblioteconomía (43: 2012: Villahermosa, Tabasco, México). XLIII Jornadas Mexicanas de Biblioteconomía: memorias. México: AMBAC, 2012. En prensa. 
El patrimonio cultural de México. E. Florescano, comp. México: CNCA, Fondo de Cultura Económica, 1993. 424 p.

Picardo, Oscar. Pedagogía informacional: enseñar a aprender en la sociedad del conocimiento [en línea]. En: Organización de Estado Iberoamericanos para la Educación, la Ciencia y la Cultura. 12 p. <http://www.oei.es/ revistactsi/numero3/art04.htm> [Consulta: enero 2013].

Porlán, Rafael. Constructivismo y enseñanza de las ciencias. España: DIADA editora, 1995. 201 p.

Pozo, Juan Ignacio. Aprendices y maestros: la psicología cognitiva del aprendizaje. España: Alianza Editorial, 2008. 614 p.

Ríos, Jaime. La biblioteca pública: un lugar de valores. En: Memoria del segundo encuentro internacional sobre bibliotecas públicas: "Modelos de biblioteca pública en Iberoamérica". México: Consejo Nacional para la Cultura y las Artes; Dirección General de Bibliotecas; Gobierno del Estado de Jalisco; Secretaría de Cultura, 2003, p. 311-322.

Didáctica de la bibliotecología: teoría y principios desde la enseñanza. México: unam, Centro Universitario de Investigaciones Bibliotecológicas, 2008. 214 p.

Rugarcía, Armando. Los valores y las valoraciones en la educación. México: Trillas, 1999. 139 p.

Shera, Jesse. Los fundamentos de la educación bibliotecológica. Tr. Surya Peniche de Sánchez Mcgregor. México: Universidad Nacional Autónoma de México, 1990. 520 p.

Lo que el bibliotecario necesita saber. En: fundamentos de educación bibliotecológica. México: UNAM, Centro Universitario de Investigaciones Bibliotecológicas, 1990, p. 201-231.

Schmelkes, Sylvia. La formación de valores en la educación básica. México: Secretaría de Educación Pública, 2004. 159 p.

uNESCO. Declaración universal de la UNESCO sobre la diversidad cultural [en línea]. Organización de las Naciones Unidas para la Educación, la Ciencia y la Cultura, 2001. < http://portal.unesco.org/es/ev.php-URL_ID=13179\&URL_ DO=DO_TOPIC\&URL_SECTION=201.html > [Consulta: febrero 2010].

Memoria del mundo [en línea]: directrices para la salvaguarda del patrimonio documental. Organización de las Naciones Unidas para la Educación, la Ciencia y la Cultura, 2002. 63 p. < http://unesdoc.unesco.org/ images/0012/001256/125637s.pdf> [Consulta: enero 2010].

Museum Internacional 215 [en línea]: Heritage issues in the information society, 1. v. LIv, no. 3, 2002, 75 p. $<$ http://unesdoc.unesco.org/images/0012/001284/128485e.pdf> [Consulta: enero 2009].

Villalpando, José Manuel. Filosofía de la Educación. México: Porrúa, 1976. 364 p. 